\title{
Use of tissues embedded in epoxy resin for routine histological examination of renal biopsies
}

\author{
W. NOEL EASTHAM AND W. B. ESSEX \\ From the Department of Pathology, Monash University, and the Department of Morbid Anatomy, \\ Alfred Hospital, Melbourne, Australia
}

SYNOPSIS The production of $0.4 \mu$ thick, full-length sections from renal tissue taken by needle biopsy is achieved by formalin and osmic acid fixation and embedding in epoxy resin as for ultramicrotomy. The marked improvement in histological clarity by using this technique is illustrated by comparison with material embedded in paraffin.

Histological clarity by light microscopy depends not only on the optical qualities of the microscope but also on the thickness of the tissue sections examined. Techniques for producing ultrathin sections were developed for electron microscopy (Newman, Borysko, and Swerdlow, 1949), but the embedded specimens are so small that they are often unrepresentative of the tissue of origin. Methods for the successful preparation of thin sections for light microscopy have been described (Cathey, 1963; Ashley and Feder, 1966) but until recently (Lynn, Martin, and Race, 1966) there have been no reports of the employment of these techniques for routine processing of surgical biopsies.

The object of this paper is to describe a method for the preparation of very thin, yet adequately stained, full-length sections from renal tissue taken by needle biopsy and embedded in epoxy resin.

\section{MATERIALS AǸD METHODS}

FIXATION The cylinder of renal tissue obtained by percutaneous needle biopsy is immediately transferred to $10 \%$ buffered formol saline $(p \mathrm{H} \mathrm{7})$ at room temperature. The period of formalin fixation should not be less than 12 hours but may be much longer: fixation for several days does not appear to have adverse effects (Baker and McCrae, 1966). When fixed, the specimen is placed in a $15 \mathrm{ml}$ glass tube from which it need not be removed until the stage of embedding. It is washed in phosphatebuffered saline $(0 \cdot 145 \mathrm{M} \mathrm{NaCl}, 0 \cdot 01 \mathrm{M}$ phosphate, $p \mathrm{H} \mathrm{7 \cdot 1)}$ for at least 30 minutes with two changes of fluid and, if desired, it may be left overnight at $4^{\circ} \mathrm{C}$ in the buffered saline. After the washing, the tissue is post-fixed in a solution of $1 \%$ osmium tetroxide (equal parts of the phosphate buffer and $2 \%$ osmium tetroxide in distilled water) for 90 minutes. This is followed by further washing

Received for publication 20 May 1968. in phosphate-buffered saline for at least 30 minutes and until the odour of the osmium fixative is dissipated.

DEHYDRATION This is achieved by adding increasing concentrations of acetone to the tube. The buffered saline is decanted and replaced by $30 \%$ acetone which is followed at half-hourly intervals by a single change of $70 \%$ acetone and six changes of $100 \%$ acetone.

EMBEDDING The acetone is replaced by $30 \%$ Araldite (Ciba Ltd, Basle) in dry acetone, penetration being assisted by gentle mechanical agitation for 30 minutes at room temperature. A $70 \%$ mixture is then substituted for the $30 \%$ mixture and agitation continued for 30 minutes at room temperature and 30 minutes in a $60^{\circ} \mathrm{C}$ oven. Finally, the $70 \%$ mixture is replaced by $100 \%$ Araldite and the specimen kept at $60^{\circ} \mathrm{C}$ with intermittent gentle stirring for a further 30 minutes. Embedding is completed by leaving the specimen in $100 \%$ Araldite at $60^{\circ} \mathrm{C}$ for 24 to 48 hours, by which time polymerization of the resin will have taken place. The embedding chamber must consist of polypropylene or some similar substance which will not adhere to the hardened Araldite and can be easily peeled off (Anderson and Doane, 1967). Almost any plastic cap provided for many commercial containers will serve.

SECTIONING Araldite blocks, on removal from the embedding chamber, are trimmed with a small handsaw, leaving the block surface to be more carefully prepared with scalpel or razor blade. An ultramicrotome is essential for cutting sections less than $1 \mu$ in thickness but the less elaborate models are best suited to the production of full-length sections. An A. F. Huxley pattern, Cambridge ultramicrotome was used to produce the sections described below. This instrument has a simple specimen holder which is easily replaced by an improvised modification designed to hold the linear blocks in a vertical position (Fig. 1). A glass knife is used: it can be made by hand (Latta and Hartmann, 1950; Pease, 1964a) or more 


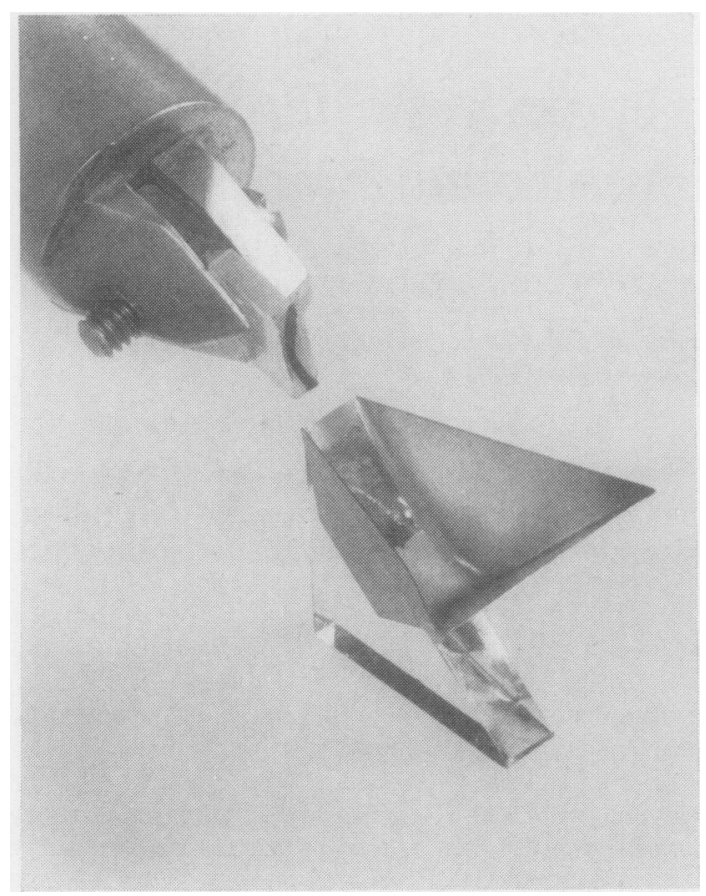

FIG. 1. Araldite-embedded specimen and modified specimen holder. The block is held vertically above the glass knife edge and attached water trough. $\times 1 \cdot 25$.

conveniently on a knife-making machine (LKB Sweden, 1963). Final trimming of the block before sectioning is carried out on the ultramicrotome and the knife is changed for making the thin sections. These can be floated off in the same way as for electronmicroscopy, by using a small metal water trough behind the cutting edge of the knife (Fig. 1) to catch the sections (Pease, 1964b). Fulllength sections as thin as $0 \cdot 2 \mu$ can be obtained but optimal staining is achieved with sections in the region of $0.4 \mu$ thick. The section is removed from the water trough with a fine glass rod and placed onto the meniscus of a drop of water on the microscope slide. Adequate adhesion of the section to the slide is achieved by drying the slide on a hot-plate which is thermostatically controlled to maintain a temperature of $65^{\circ} \mathrm{C}$.

STAINING Sections prepared in this manner are often difficult to stain satisfactorily. This is due primarily to the barrier afforded by the embedding resin and secondarily to the extreme thinness of the tissue section itself (Pease, 1964c). Adequate results, however, are obtainable with metachromatic dyes, or the commercial preparation Paragon (Paragon C \& C Co. Inc. N.Y.). The method of staining is a modification of a technique used by Charles and Meek (Pease, 1964d). The section is covered with 1 drop of the dye and 3 drops of a $2 \%$ borax solution $\left(2 \mathrm{~g} \mathrm{Na} \mathrm{B}_{4} \mathrm{O}_{7} \cdot 10 \mathrm{H}_{2} \mathrm{O}\right.$ in $100 \mathrm{ml}$ distilled $\mathrm{H}_{2} \mathrm{O}$ ). The slide is again heated in the manner described above, for 15 to 30 seconds. After washing with distilled water the section is dried once more on the hot-plate for five minf euts, dipped in xylol and then mounted in neutral D.P.X으․

Examples of glomerular histology as seen in 0.4 sections taken from 10 renal biopsies are described t $\$$ illustrate the value of the method in a variety of condition? Two postmortem specimens were also processed; the first was from a normal kidney removed and perfuser with formalin within 10 minutes of death; the second was from routine formalin-fixed tissue severely affected by amyloidosis. The biopsies were formalin-fixed specimens and were bisected on arrival at the laboratory to perm饲 comparison of the Araldite sections with conventionà paraffin processing. Paraffin-embedded sections were cle $\overrightarrow{d b}$ at $4 \mu$ on a Leitz-Minot microtome and stained wit haematoxylin and eosin, the periodic-acid-Schiff techniqueg and Masson's trichrome stain. All sections were examineid and photographed with a Leitz Ortholux microscope. The Araldite-embedded specimens were especially suited to high-power oil immersion examination, but the paraffin sections are too thick for similar study and af best viewed through lower power dry objectives. The comparative photomicrographs were taken under the microscopic conditions which proved most informative for the paraffin-embedded sections this was at a magnat fication of $\times \mathbf{4 0 0}$ using $\times \mathbf{4 0}$ dry objective and for the Araldite-embedded tissues at a magnification of $\times 1,00 \mathrm{~g}$ using the $\times 100$ oil immersion objective.

\section{RESULTS}

NORMAL KIDNEY The clarity of detail afforded by the Araldite embedding and sectioning technique demonstrated in Figure 2. Endothelial and epithelia cells can be readily distinguished by their relative sizes and their relationship to the capillary loop. The larger epithelial cells embrace the outer aspect of the loops with extensions of cytoplasm and numerous foot processes. Only occasionally can these cells be identified with certainty in the paraffin-embedded material (Fig. 3). In the resin-embedded section the mesangial areas, consisting of mesangial cells and matrix, are clearly defined; in the paraffin section thef are seen only as slight focal thickenings of the basement membrane so that positive identification not always possible.

MINIMAL LESION One example of such a lesion wog studied. The patient presented with the features of the nephrotic syndrome, renal biopsy being suR sequently performed on two separate occasions. No significant renal lesion was observed on examinatio of any of the paraffin-embedded material (Fig. Examination of the Araldite sections (Fig. confirmed the absence of basement membrane changes but the glomerular epithelial cells were see to have lost their clear cytoplasmic borders and the was fusion of foot processes in several areas. These features were subsequently confirmed by electro® microscopy. 


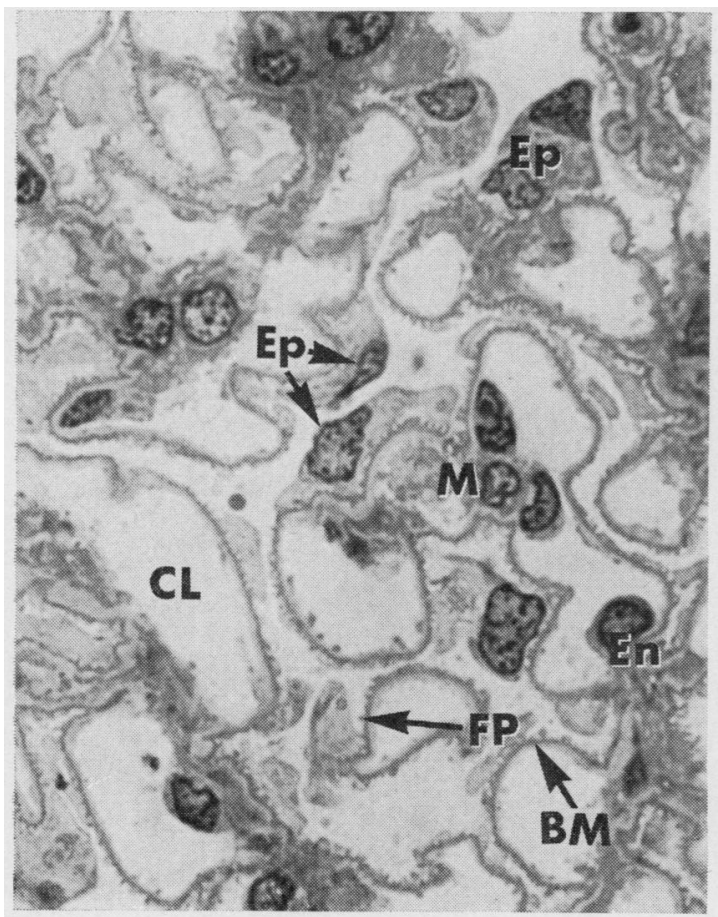

FIG. 2. Normal glomerulus. Araldite-embedded section. Paragon stain $\times 3,000$.

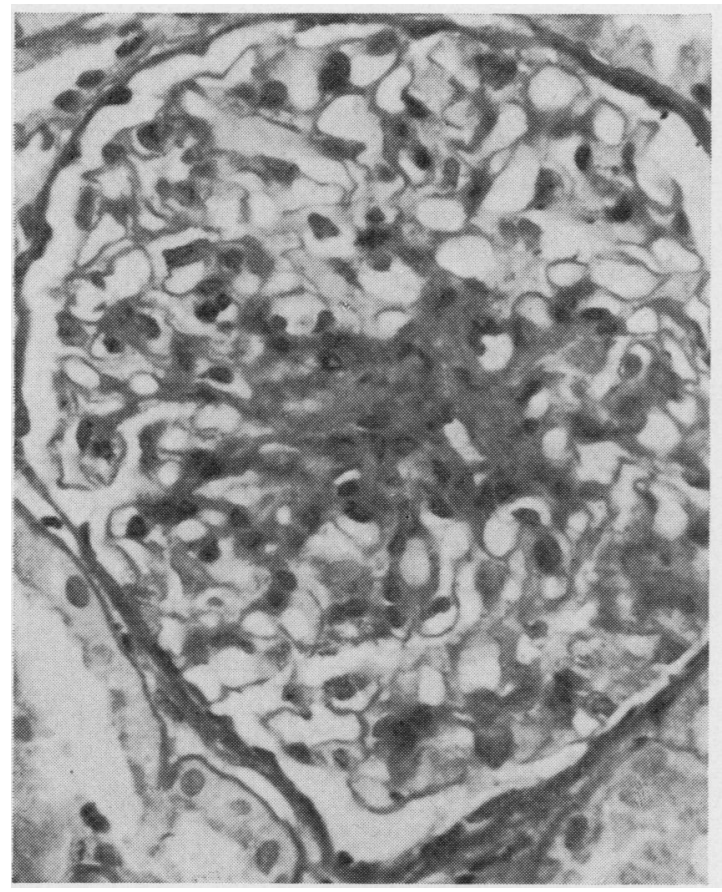

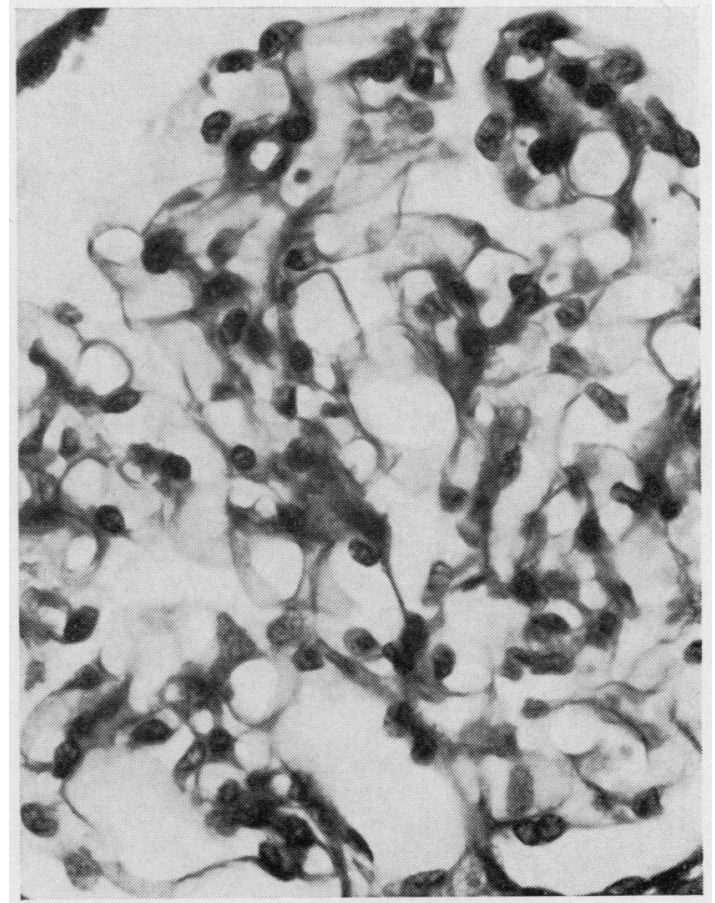

FIG. 3. Normal glomerulus. Paraffin-embedded section. $P A S \times 1,070$.

$$
\begin{aligned}
C L & =\text { capillary loop } \\
E p & =\text { epithelial cell } \\
E n & =\text { endothelial cell } \\
B M & =\text { basement membrane } \\
M & =\text { mesangial cell } \\
N & =\text { large nodular deposition } \\
F P & =\text { foot processes } \\
D & =\text { deposit } \text { within the basement membrane } \\
R B C & =\text { erythrocytes } \\
W B C & =\text { leucocytes } \\
B C & =\text { Bowman's capsule }
\end{aligned}
$$

FIG. 4. Minimal lesion. Paraffin-embedded section. $P A S \times 1,070$. 


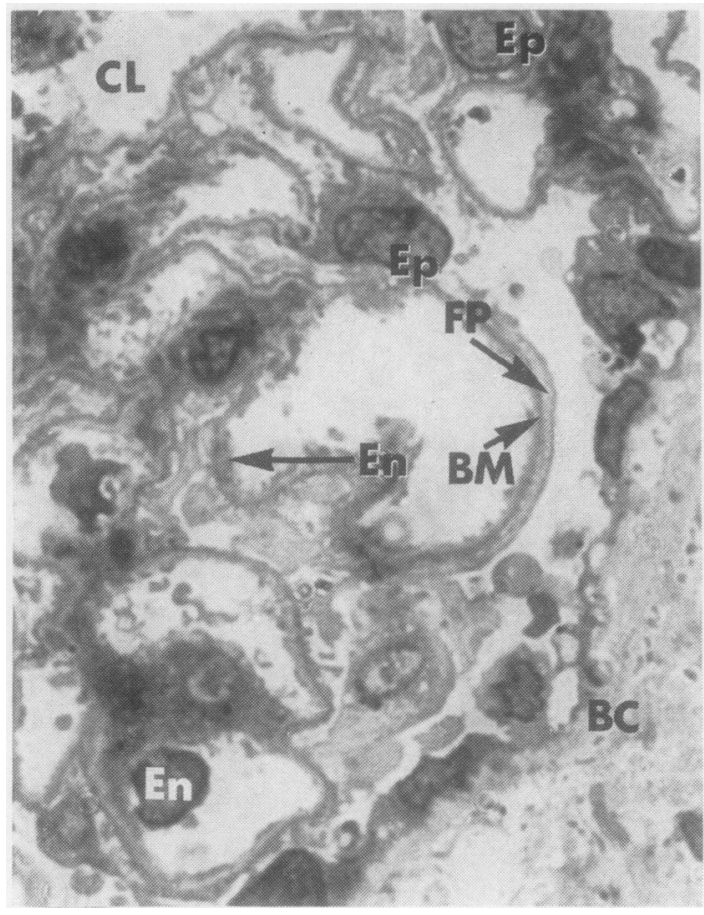

FIG. 5. Minimal lesion. Araldite-embedded section. Paragon stain $\times 3,000$.

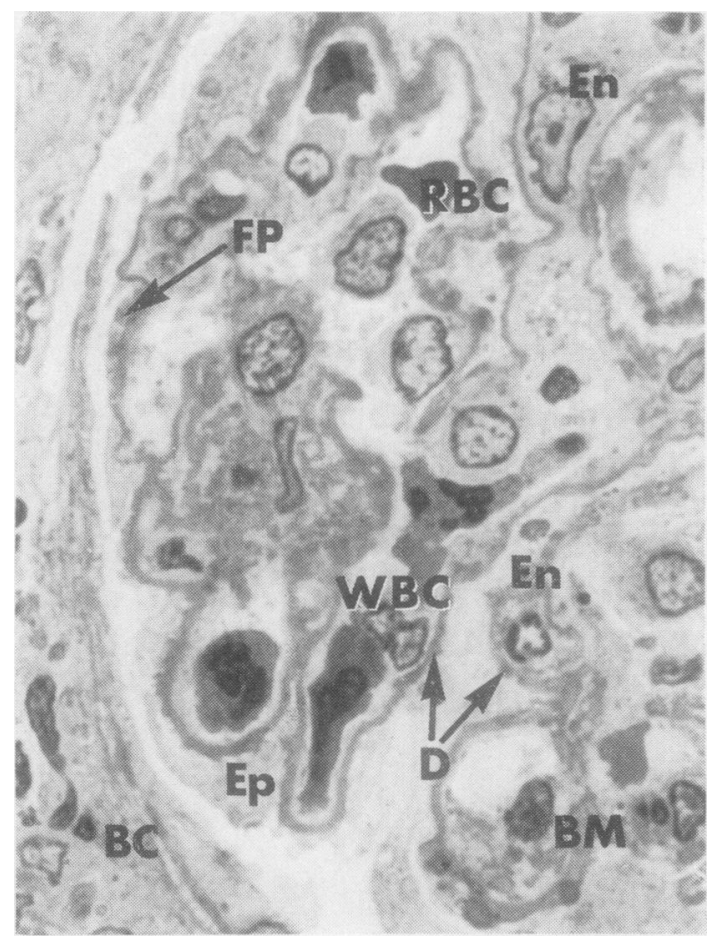

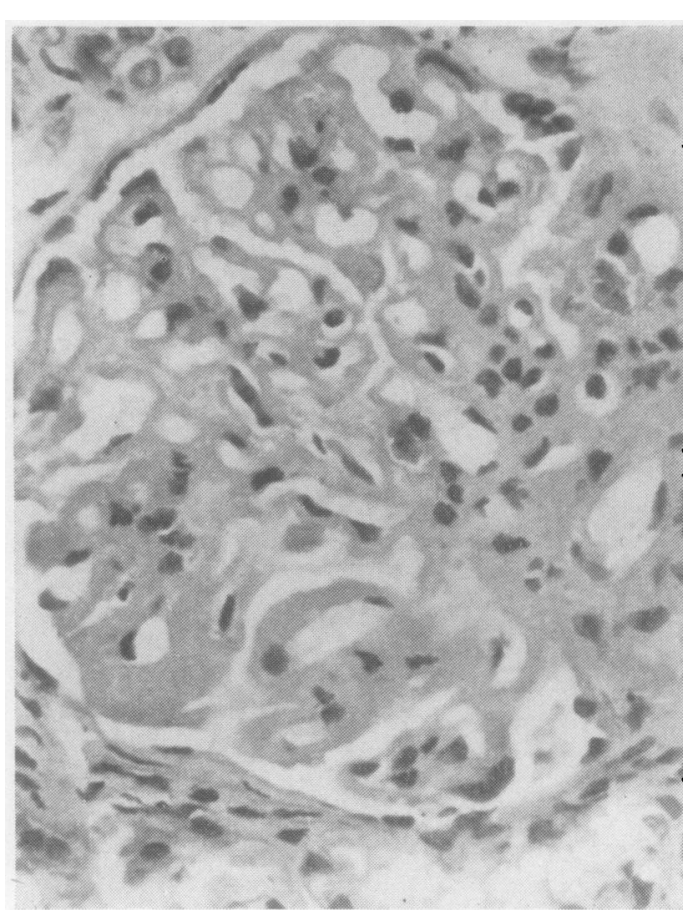

FIG. 6. Systemic lupus erythematosus kidney. Paraffie embedded section. PAS $\times 1,060$.

$\begin{aligned} C L & =\text { capillary loop } \\ E p & =\text { epithelial cell } \\ E n & =\text { endothelial cell } \\ B M & =\text { basement membrane } \\ M & =\text { mesangial cell } \\ N & =\text { large nodular deposition } \\ F P & =\text { foot processes } \\ D & =\text { deposit within the basement membrane } \\ R B C & =\text { erythrocytes } \\ W B C & =\text { leucocytes } \\ B C & =\text { Bowman's capsule }\end{aligned}$

FIG. 7. Systemic lupus erythematosus kidney. Araldifo embedded section. Paragon stain $\times 3,000$. 


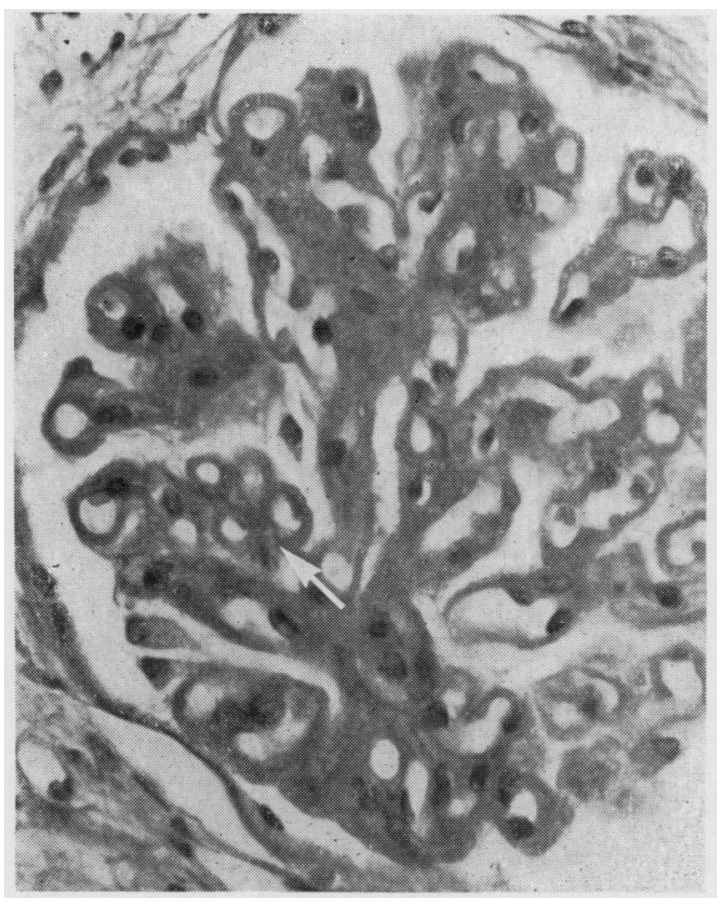

FIG. 8.

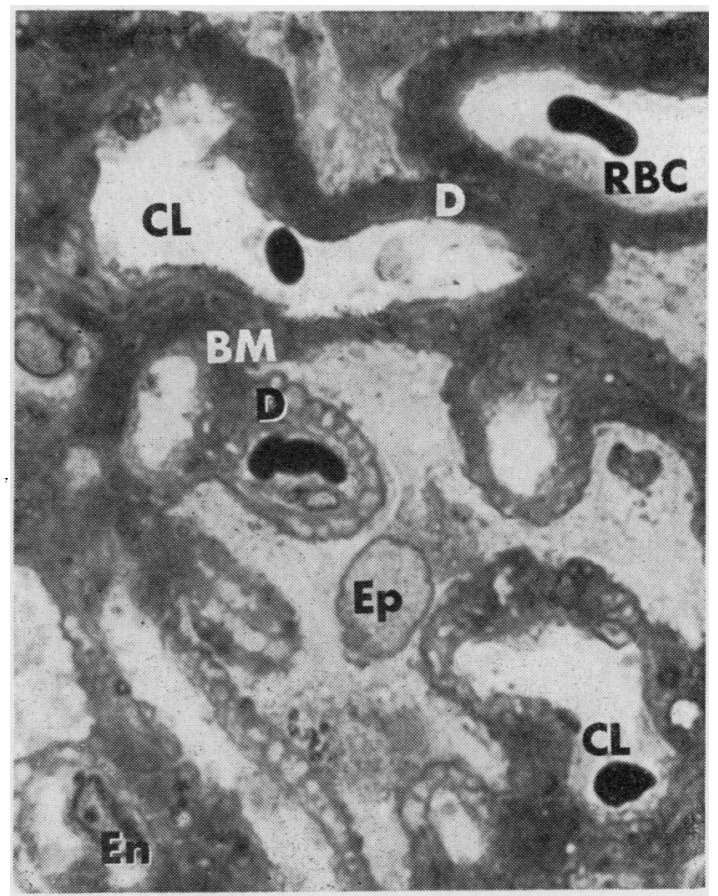

FIG. 9.

FIG. 8. Membranous glomerulonephritis. Case 1. Paraffin-embedded section. Arrow indicates areas of rarified basement membrane density. PAS $\times 1,060$.

FIG. 9. Membranous glomerulonephritis. Case 1. Araldite-embedded section. Paragon stain $\times 3,000$.

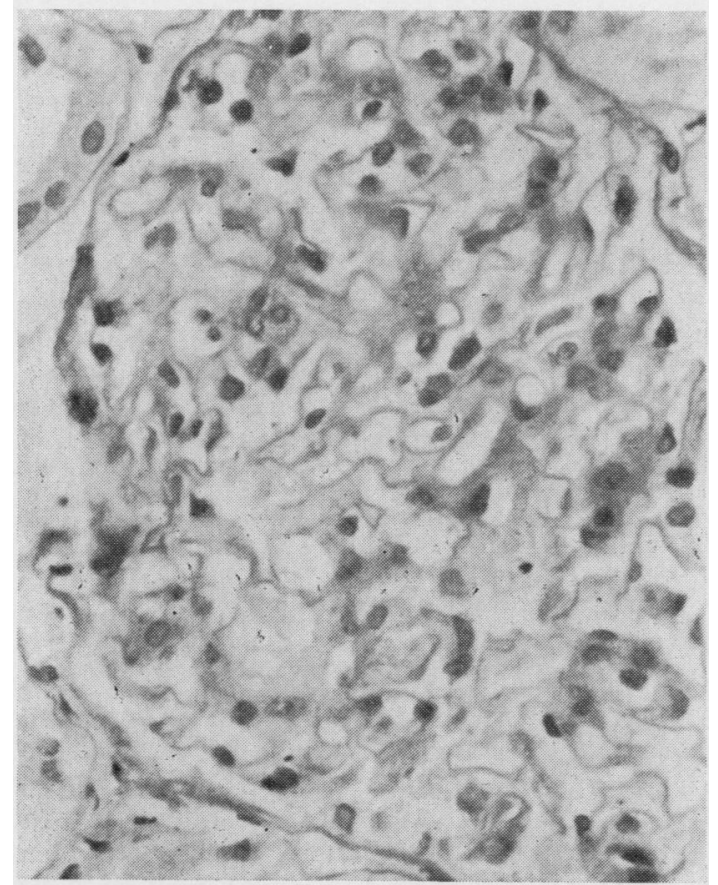

FIG. 10. Membranous glomerulonephritis. Case Parafin-embedded section. PAS $\times 1,060$.

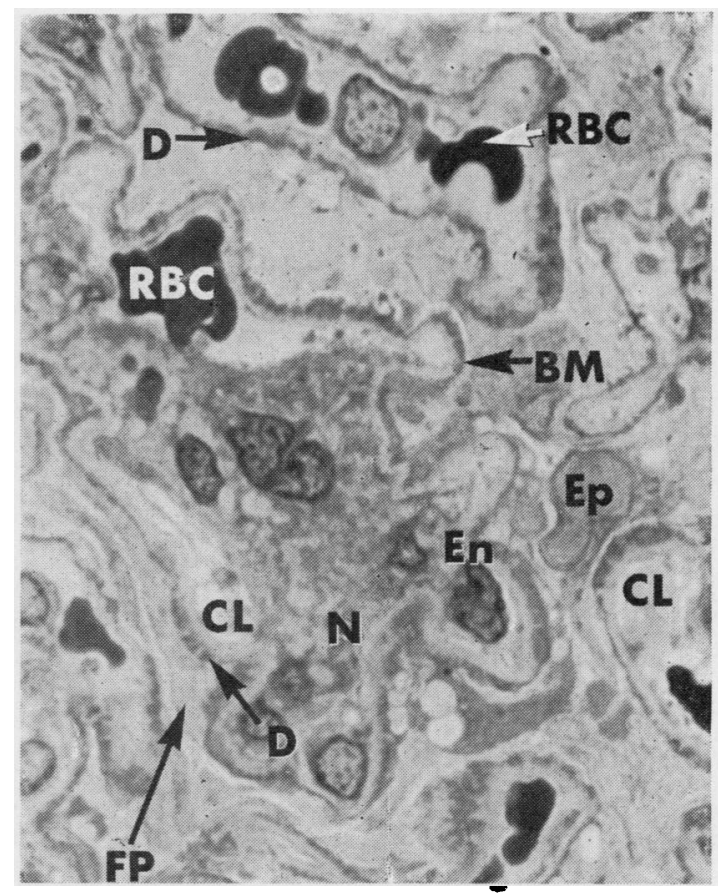

FIG. 11. Membranous glomerulonephritis. Case 2. Araldite-embedded section. Paragon stain $\times 3,000$. 


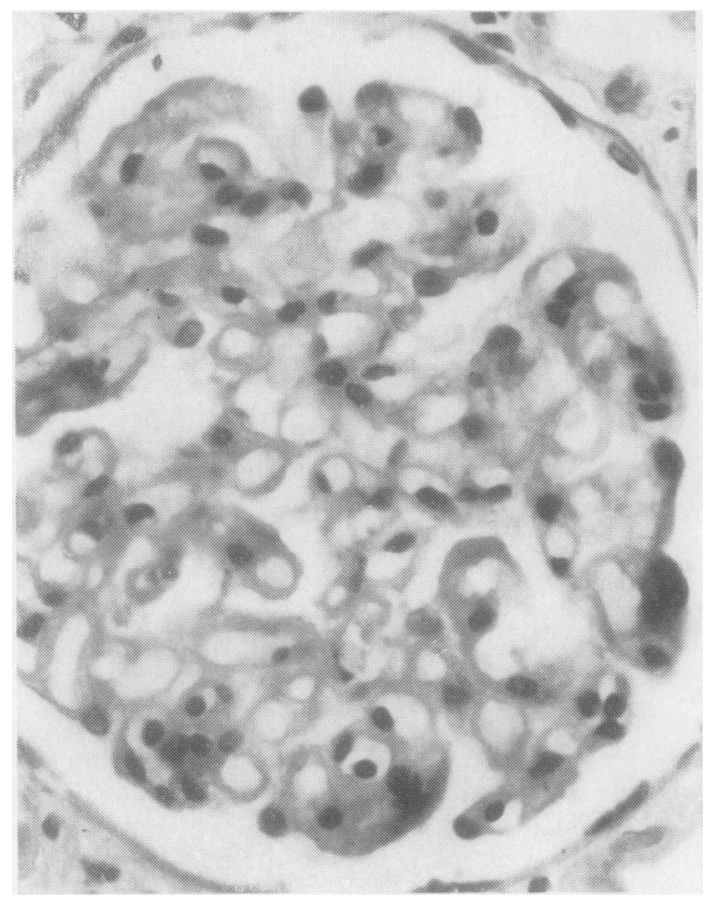

FIG. 12. Membranous glomerulonephritis. Case 3 Paraffin-embedded section. PAS $\times 1,060$.

$$
\begin{aligned}
C L & =\text { capillary loop } \\
E p & =\text { epithelial cell } \\
E n & =\text { endothelial cell } \\
B M & =\text { basement membrane } \\
M & =\text { mesangial cell }
\end{aligned}
$$

SYSTEMIC LUPUS ERYTHEMATOSUS One case was examined, the diagnosis being made on paraffinembedded material (Fig. 6), which showed a generalized but irregular increase in the thickness of the basement membrane and 'wire-looping' in the peripheral parts of the glomerular tuft. In addition to these changes the Araldite sections (Fig. 7) revealed distinct nodular deposits within the basement membrane, partial occlusion of the capillary spaces by endothelial cell debris and polymorphonuclear leucocytes, foot process fusion, and disintegration of epithelial cells.

MEMBRANOUS GLOMERULONEPHRITIS Of the three biopsies which were ultimately classified as membranous glomerulonephritis, only two were recognized as such on examination of the paraffinembedded material.

The first case showed marked thickening of the glomerular basement membrane which was clearly

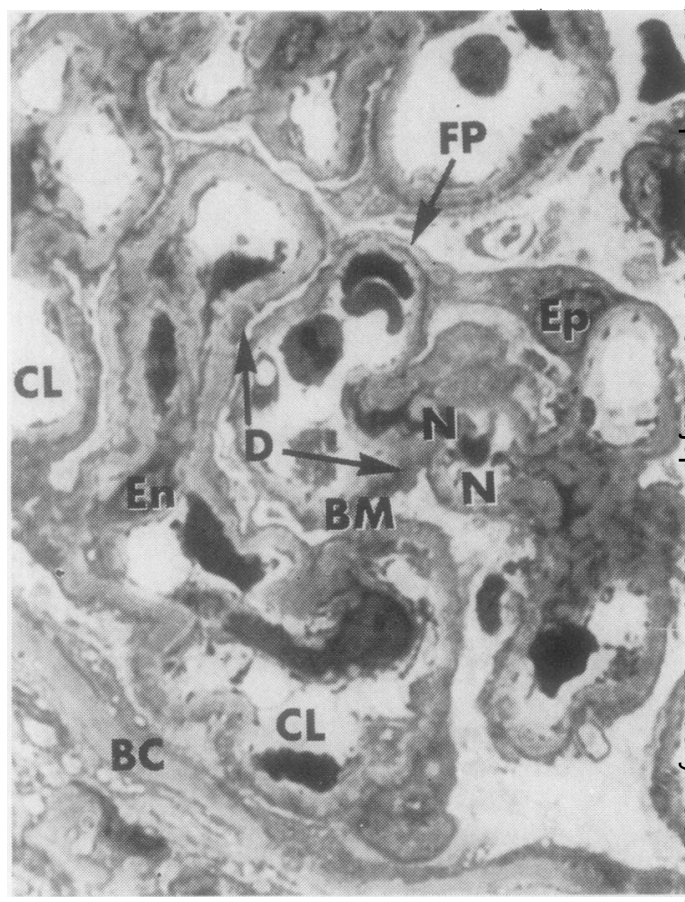

FIG. 13. Membranous glomerulonephritis. Case Araldite-embedded section. Paragon stain $\times 3,000$.

$N=$ large nodular deposition

$F P=$ foot processes

$D=$ deposit within the basement membrane

$R B C=$ erythrocytes

$W B C=$ leucocytes

visible in the paraffin sections (Fig. 8). Examination of Araldite sections (Fig. 9) confirmed this argd in addition revealed both dense and rarified zones within the thickened membranes, the low density areas resembling vacuoles. These could be identified on retrospective examination of the paraffin sections (Fig. 9). Other features, recognizable only in the $0.4 \mu$ sections, were early degenerative changes of the epithelial cells with lipid droplet accumulation and fusion of the foot processes.

Examination of paraffin-embedded sections frog the second case revealed insufficient changes To account for the clinical picture (Fig. 10). In the Araldite sections (Fig. 11), several important lesioos were noted: the basement membrane was thickened in places up to three times the normal; denge deposits, mainly of linear distribution on the epithelial aspect of the capillary loops, were preseftit in most areas and were accompanied by epithelfat cell degeneration and foot process fusion. 


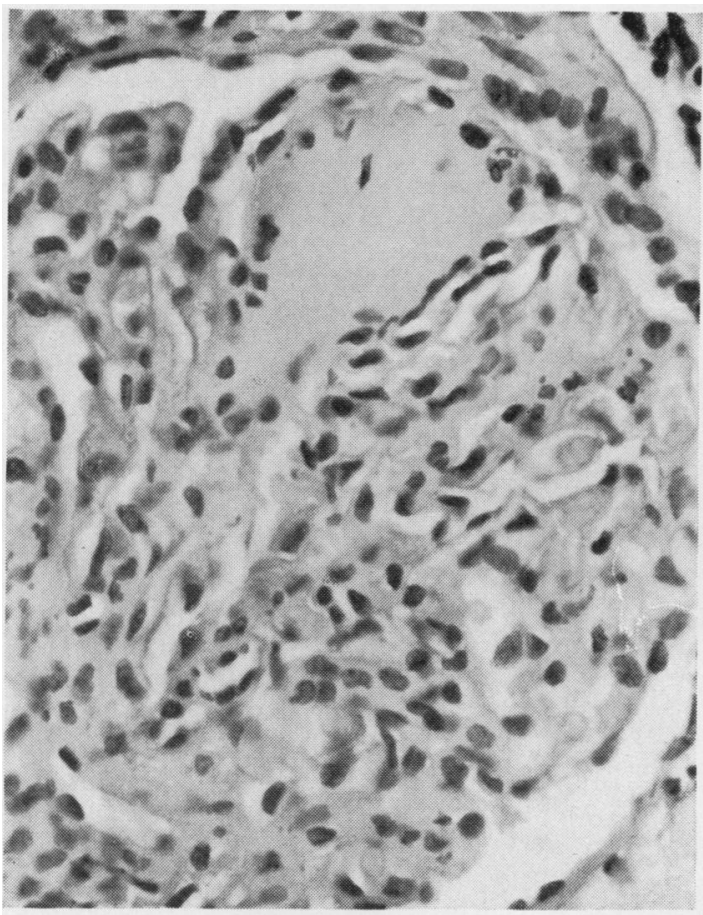

FIG. 14. Diabetic glomerulosclerosis. Paraffin-embedded section. $H \& E \times 1,060$.

Similar changes were also seen in the third case, although the degree of basement membrane thickening was so marked and uniform in its distribution that the diagnosis was readily apparent on examination of the paraffin sections alone (Fig. 12). The resin-embedded sections showed deposits and thickening of the membrane by at least four times (Fig. 13).

PROLIFERATIVE GLOMERULONEPHRITIS Diagnosis of the single case examined was based on glomerular hypercellularity, digitation of the tuft, capsular adhesions, and occasional crescent formation as observed in the paraffin-embedded sections. An increase in the PAS-positive material was also noted in the mesangial areas. These observations were confirmed on examination of the Araldite sections, which revealed additional features, namely, enlarged mesangia appearing to enclose several nuclei of apparently endothelial origin, basement membrane thickening confined to portions of capillary loops adjacent to the mesangia, and degenerative changes in epithelial cells.

RAPIDLY PROGRESSIVE GLOMERULONEPHRITIS TWO cases were included under this heading on the basis

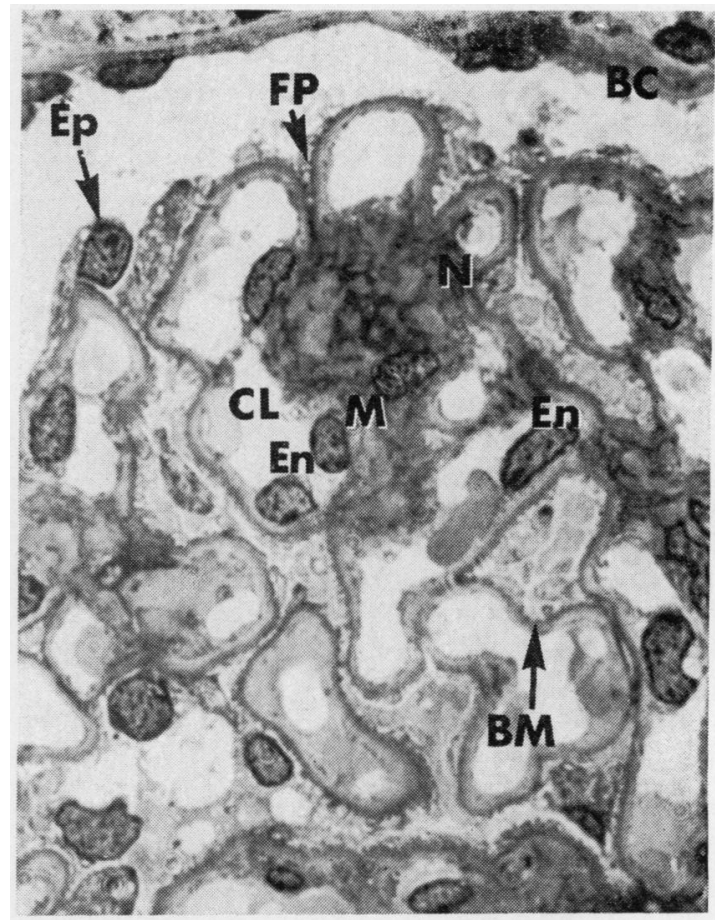

FIG. 15. Diabetic glomerulosclerosis. Araldite-embedded section. Paragon stain $\times 3,000$.

of clinical data and advanced glomerular fibrosis. The resin-embedded material did not contribute significantly to the information already obtained from examination of the paraffin sections.

DiABETIC GLOMERULOSClerosis Paraffin-embedded material from a single case (Fig. 14) showed both nodular and diffuse lesions characteristic of diabetic glomerulosclerosis. The Araldite sections (Fig. 15) did not contribute further information but it was apparent that they could help in the detection of lesser thickening of the basement membrane.

AMYLoIDOsIS Although staining reactions are reduced with resin-embedded section, metachromasia is still obtained and the fine distribution of amyloid deposits is readily analysed.

\section{COMMENT}

There are several advantages in preparing very thin sections for routine histological diagnosis. Histological detail is better than with conventional thicker sections and they less often require special stains for the detection of marginal degrees of basement membrane thickening. They also provide a useful link with the ultrastructural picture afforded by 
electron microscopical examination. Ultrastructural studies are usually restricted to an individual glomerulus, but the $0.4 \mu$ sections permit whole biopsy examination including vessels, tubules, interstitium, and perhaps several glomeruli, at any one time.

The use of formalin as the basic fixative avoids the complications of inexperienced theatre and ward staff handling a variety of special fixatives for different purposes. It has been previously shown (Baker, 1965) that formalin-fixed tissues are adequate for some ultrastructural studies which means that once the tissues have been embedded in an epoxy resin further sections can be prepared later for electron microscopical examination should these be required. The post-fixation period with osmium tetroxide in the laboratory helps to clarify the cytoplasmic details, cell boundaries, and membranes: it must not be omitted, especially if ultrastructural investigations are ultimately contemplated.

The technique is not restricted to renal biopsies but can be employed for a much wider range $\stackrel{\frac{D}{\vec{Q}}}{\underline{\sigma}}$ tissues.

The authors wish to thank Mr G. S. Lynraven, electren microscopist, for technical advice, Professor R. C. NaEn for helpful guidance, and Mrs R. Clark for assistange with the preparation of the photomicrographs.

\section{REFERENCES}

Anderson, N., and Doane, F. W. (1967). Stain Technol., 42, 169. $\vec{\circ}$ Ashley, C. A., and Feder, N. (1966). Arch. Path., 81, 391.

Baker, J. R. (1965). J. roy. micr. Soc., 84, 115.

$\longrightarrow$, and McCrae, J. M. (1966). Ibid., 85, 391.

Cathey, W. J. (1963). Stain Technol., 38, 213.
Latta, H., and Hartmann, J. F. (1950). Proc. Soc. exp. Biol. (N.尹), $74,436$.

LKB, Sweden (1963). Science Tools, 10, 59.

Lynn, J. A., Martin, B. S., and Race, G. J. (1966). Amer. J. clin. Patt. $45,704$.

Newman, S. B., Borysko, E., and Swerdlow, M. (1949). J. Res. huin Bur. Stand., 43, 183.

Pease, D. C. (1964a). Histological Techniques for Electron Microscopy, 2nd ed., p. 149. Academic Press, New York.

- (1964b). Ibid., p. 165.

- (1964c). Ibid., p. 256.

_-_ (1964d). Ibid., p. 260.

\section{Reports and Bulletins prepared by the Association of Clinical Biochemists}

The following reports and bulletins are published by the Association of Clinical Biochemists. They may be obtained from The Administrative Office, Association of Clinical Biochemists, 7 Warwick Court, Holborn, London, W.C.尹 The prices include postage, but airmail will be charged extra.

\section{SCIENTIFIC REPORTS}

1 Colorimeters with Flow Through Cells. A critical assessment of 4 instruments. 1965. P. M. G. BROUGHTON and C. RILEY. 13s. 6d.

2 Colorimeters. A critical assessment of 5 commercial instruments. 1966. P. M. G. BROUGHTON, C. RILEY, J. G. H. COOK, P. G. SANDERS, and H. BRAUNSBERG. $15 \mathrm{~s}$.

3 Automatic Dispensing Pipettes. An assessment of 35 commercial instruments. 1967. P. M. G. BROUGHTON, A. H. GOWENLOCK, G. M. WIDDOWSON, and K. A. AHLQUIST. 10s.

TECHNICAL BULLETINS

9 Determination of Urea by AutoAnalyzer. November 1966. RUTH M. HASLAM. 2s. 6d.
10 Filter Fluorimeters. A comparative list of 14 minstruments. March 1967. HANNELORE BRAUNSBERR. 5s.

11 Determination of Serum Albumin by AutoAnalyzer using Bromocresol Green. October 1967. B. $J_{\mathbf{E}}$. NORTHAM and G. M. WIDDOWSON. 2s. 6d.

12 Control Solutions for Clinical Biochemistry. Februs y 1968. P. M. G. BROUGHTON. 2s. 6d.

13 An Assessment of the Technicon Type II Sampler Unit. March 1968. B. C. GRAY and G. K. MCGOw 1s. $6 \mathrm{~d}$.

14 Atomic Absorption Spectroscopy. An Outline of ${ }^{?}$ ts Principles and a Guide to the Selection of Instruments. May 1968. J. B. DAWSON and P. M. O্ণG. BROUGHTON. $4 \mathrm{~s}$.

15 A Guide to Automatic Pipettes (2nd edition). Junne 1968. P. M. G. BROUGHTON. $5 \mathrm{~s}$. 